\title{
In Situ Solvent Formation Microextraction based on Ionic Liquids and 1-(2-Hydroxynaphtalene-1-yl)ethane Oxime for Determination of Zinc
}

\author{
Mehdi Hosseini, *,a Nasser Dalali, ${ }^{a}$ Saeid Mohammad Nejad ${ }^{a}$ and Rostam Jamali ${ }^{b}$ \\ ${ }^{a}$ Phase Separation \& FIA Lab., Department of Chemistry, Faculty of Science, \\ University of Zanjan, 45195-313, Zanjan, Iran \\ ${ }^{b}$ Analytical Chemistry Advanced Laboratory, Department of Chemistry, \\ University of Razi, Kermanshah, Iran
}

\begin{abstract}
Um método simples de microextração com formação de solvente in situ (ISFME) baseado no uso de líquido iônico (IL) como solvente extrator e hexafluorofosfato de sódio $\left(\mathrm{NaPF}_{6}\right)$ como agente par-iônico foi proposto para a concentração de níveis de traço de zinco. Neste método, o íon zinco foi complexado com 1-(2-hidroxinaftaleno-1-il)etano oxime (HNEO) e extraído em uma fase líquida iônica. Após a separação, o analito enriquecido na fase final foi determinado por espectrometria de absorção atômica de chama (FAAS). ISFME é um método rápido, simples e adequado para extração e concentração de inorgânicos tais como íons metálicos em soluções contendo uma elevada concentração de sal. As influências dos parâmetros analíticos na eficiência da microextração foram investigadas e otimizadas. Sob condições otimizadas, o limite de detecção e o fator de enriquecimento foram $0,05 \mu \mathrm{g} \mathrm{L} \mathrm{L}^{-1}$ and 81 , respectivamente. O desvio padrão relativo (R.S.D.) obtido foi $0,8 \%$. A exatidão do método foi confirmada pela análise de materiais de referência certificados. O método apresentado foi aplicado com êxito na determinação de zinco em amostras de zinco.
\end{abstract}

A simple in situ solvent formation microextraction (ISFME) method based on use of ionic liquid (IL) as extractant solvent and sodium hexafluorophosphate $\left(\mathrm{NaPF}_{6}\right)$ as ion-pairing agent was proposed for the concentration of trace levels of zinc. In this method, zinc ion was complexed with 1-(2-hydroxynaphtalene-1-yl)ethane oxime (HNEO) and extracted into an ionic liquid phase. After phase separation, the enriched analyte in the final solution was determined by flame atomic absorption spectrometry (FAAS). ISFME is a fast, simple and suitable method for extraction and concentration of inorganic such as metal ions from sample solutions containing a high concentration of salts. The influences of the analytical parameters on the microextraction efficiency were investigated and optimized. Under the optimum conditions, the limit of detection and the enhancement factor were $0.05 \mu \mathrm{g} \mathrm{L}^{-1}$ and 81 , respectively. The relative standard deviation (R.S.D.) was obtained $0.8 \%$. The accuracy of the method was confirmed by analyzing certified reference materials. The presented method was successfully applied for the determination of zinc in water samples.

Keywords: zinc, in situ solvent formation microextraction, ionic liquid, flame atomic absorption spectrometry

\section{Introduction}

The determination of heavy metals in foods, and drinking and irrigation waters has become an important part of most studies concerned with environmental pollution and occupational health hazards. Although it is difficult to classify trace metals into essential and

*e-mail: mehdihosseini_znu@yahoo.com toxic groups, yet it is well known that an essential metal becomes toxic at sufficiently high intakes. ${ }^{1}$ Even though zinc is an essential requirement for a healthy body, excess of zinc can be harmful and causes zinc toxicity. ${ }^{2}$ Excessive absorption of zinc can suppress copper and iron absorption. The free zinc ion in solution is highly toxic to plants, invertebrates and even vertebrate fish. The free ion activity model (FIAM) is well-established in the literature, and shows that just micromolar amounts of the 
free ion kill some organisms. A recent example showed $6 \mu \mathrm{mol} \mathrm{L}{ }^{-1}$ killing $93 \%$ of all daphnia in water. The free zinc ion is also a powerful Lewis acid up to the point of being corrosive. Stomach acid contains hydrochloric acid, in which metallic zinc readily dissolves to give corrosive zinc chloride. Swallowing a post-1982 American one cent piece $(97.5 \%$ zinc) can cause damage to the stomach lining due to the high solubility of the zinc ion in the acidic stomach. ${ }^{3}$ Therefore, a precise, accurate and rapid measurement of zinc is much interesting. Different analytical techniques have been reported to determine zinc in various samples including flame atomic absorption spectrometry (FAAS), graphite furnace atomic absorption spectrometry (GFAAS), inductively coupled plasma optical emission spectrometry (ICP OES), inductively coupled plasma mass spectrometry (ICP-MS) differential pulse stripping voltammetry, ion chromatography and molecular absorption spectrophotometry. ${ }^{4}$

From the analytical tools above listed, flame atomic absorption spectrometry is widely used because of low costs, operational facility and high sample throughput. ${ }^{5-8}$ However, conventional FAAS has a limit of detection that is not low enough to determine zinc at trace levels in several types of matrix. Therefore, a preconcentration and separation steps are needed prior to analyte determination by flame atomic absorption spectrometry.

In inorganic trace analysis, preconcentration of desired trace elements is frequently required prior to the instrumental determination to lower the limits of detection, improve the precision and accuracy of the analytical results, and to widen the scope of the determination techniques. ${ }^{9}$ The continuous quest for novel sample preparation and preconcentration procedures has led to the development of new methods such as solid-phase microextraction (SPME),${ }^{10}$ stir bar sorptive extraction (SBSE), ${ }^{11}$ single drop microextraction (SDME) ${ }^{12}$ hollow fiber-liquid phase microextraction (HF-LPME), ${ }^{13}$ cloud point extraction $(\mathrm{CPE}),{ }^{14}$ solid phase extraction (SPE),${ }^{15}$ dispersive liquid-liquid microextraction (DLLME) ${ }^{16}$ and cold-induced aggregation microextraction (CIAME). ${ }^{17}$

The main advantages of the mentioned techniques are their high speed and negligible volume of the used solvent. However, in the presence of high content of salts their performance decreases, significantly. ${ }^{18}$ Room-temperature ionic liquids (RTILs) are being recently considered as replacement solvents in the sample preparation because of their unique chemical and physical properties such as negligible vapor pressure, non-flammability, good extractability for various organic compounds and metal ions as a neutral or charged complexes, as well as tunable viscosity and miscibility with water and organic solvents. ${ }^{19}$
By definition, ionic liquids are known as solvents entirely consisting of ionic species and do have melting points close or below room temperature. Ionic liquids consist of a salt where one or both the ions are large, and the cations have low degree of symmetry. ${ }^{20}$ Ionic liquids (ILs) are proving to be increasingly interesting fluids for application in soft-matter material systems from electrochemistry to energetic materials, and are also studied as potential solvents in separation processes. ${ }^{21,22}$ Properties, including low melting points, wide liquid ranges and negligible vaporpressure, have encouraged researchers to explore the uses of ILs to replace volatile organic solvents (VOCs).

This paper is aimed at developing a microextraction technique against very high content of salts. Among the different sample preparation methods, a new mode of homogeneous liquid-liquid microextraction (HLLME) based on ILs, termed in situ solvent formation microextraction (ISFME), was developed in the present research. In ISFME, there is no interface between water and extractant phases. During the formation of fine droplets of the extractant phase, the extractant molecules collect the hydrophobic species, and the extraction process is complete after formation of the droplets. As a result, mass transfer from aqueous phase into separated phase has no significant effect on the extraction step. In the presence of high content of salt, the solubility of ILs increases and the phase separation cannot occur. However, according to the common ion effect, the solubility of ILs decreases in the presence of common ion. Consequently, the volume of the extractant phase does not alter. Because of high density of ILs, even in the saturated solutions $(40 \%, \mathrm{w} / \mathrm{v})$, the fine droplets of extractant phase can settle. Due to very low solubility of water in the hydrophobic ILs, the residual salinity from the matrix is negligible. Rather than the other technique that are used for concentration of heavy metal ions, ISFME is faster and simpler and is applicable for solutions containing higher concentration of salts. For evaluating the performance of ISFME, zinc was selected as a test analyte and determined in water samples using atomic detection.

\section{Experimental}

\section{Instrumentation}

The measurements of zinc ions were performed with a Varian specterAA-220 flame atomic absorption spectrometer equipped with a hollow cathode lamp and a deuterium background corrector. The hollow cathode lamp of zinc was operated at $4 \mathrm{~mA}$, using the wavelength at $213.9 \mathrm{~nm}$, slit of $0.2 \mathrm{~nm}$, burner height of $8 \mathrm{~mm}$ and 
acetylene gas flow rate of $1.5 \mathrm{~L} \mathrm{~min}^{-1}$. All measurements were carried out in peak area mode (measurement time of 3 s). A HERMLE centrifuge equipped with a swing out rotor (4-place, 6000 rpm, Cat. No. Z 360) was obtained from Hettich (Kirchlengern, Germany). A Metrohm digital pH-meter (model 692, Herisau, Switzerland), equipped with a glass-combination electrode, was used for $\mathrm{pH}$ adjustment.

\section{Reagents}

All the used reagents in this work were of analytical grade of Merck (Darmstadt, Germany). Sodium hexafluorophosphate $\left(\mathrm{NaPF}_{6}\right)$ was purchased from ACROS (Geel, Belgium). All aqueous solutions were prepared in double-distilled water. Working standard solutions were obtained by appropriate stepwise dilution of the stock standard solution $\left(1000 \mathrm{mg} \mathrm{L}^{-1}\right.$ solution of zinc in $0.1 \mathrm{~mol} \mathrm{~L}^{-1}$ nitric acid). Working solutions (ILs), 1-hexyl-3-methylimidazolium tetrafluoroborate $[\mathrm{Hmim}]\left[\mathrm{BF}_{4}\right], 0.6 \mathrm{mg} \mu \mathrm{L}^{-1}$, were prepared in ethanol. A solution of $100 \mathrm{mg} \mathrm{NaPF}_{6}$ was prepared by dissolving an appropriate amount of $\mathrm{NaPF}_{6}$ in doubly distilled water. A solution of HNEO (Figure 1) that was synthesized as literatures ${ }^{23-25}\left(2.0 \times 10^{-2} \mathrm{~mol} \mathrm{~L}^{-1}\right)$ was prepared by dissolving an appropriate amount of this chelating agent in ethanol. The water certified reference material (GBW07602) was purchased from National Research Center for Certified Reference Materials (Beijing, China).<smiles>CC(=NO)c1c(O)ccc2ccccc12</smiles>

Figure 1. Chemical structure of 1-(2-hydroxynaphtalene-1-yl)ethane oxime (HNEO).

\section{ISFME procedure}

A $5 \mathrm{~mL}$ of the sample solution (or standard solution) containing zinc ion, HNEO $\left(2.0 \times 10^{-2} \mathrm{~mol} \mathrm{~L}^{-1}\right)$, and $[\mathrm{Hmim}]\left[\mathrm{BF}_{4}\right](30 \mathrm{mg})$ was transferred to $10 \mathrm{~mL}$ screw-cap conical-bottom glass centrifuge tube. After shaking, $0.6 \mathrm{~mL}$ $\mathrm{NaPF}_{6}(100 \mathrm{mg})$ was added to the solution and a cloudy solution was formed. Then, the mixture was centrifuged for $5 \mathrm{~min}$ at $4000 \mathrm{rpm}$. As a result, the fine droplets of IL settled at the bottom of the centrifuge tube. Aqueous phase was simply removed by inverting the tubes. Subsequently, IL-phase was dissolved in $50 \mu \mathrm{L}$ ethanol solution and it was aspirated to the flame atomic absorption spectrometer.

\section{Results and Discussion}

Effect of $\mathrm{pH}$

$\mathrm{pH}$ plays an important role on the metal-chelate formation and subsequent extraction. The separation of metal ions in aqueous phase into IL-phase by ISFME involves prior complex formation with sufficient hydrophobicity to be extracted. The influence of $\mathrm{pH}$ of the sample solutions on the extraction efficiency was studied in the $\mathrm{pH}$ range of 2.0-8.0. The $\mathrm{pH}$ of sample solution was adjusted using $\mathrm{HCl}$, acetate/acetic acid and $\mathrm{NaOH}$. According to the obtained results (Figure 2), the absorbance was relatively constant in the $\mathrm{pH}$ range of 4.0-6.0. Thus, a $\mathrm{pH}$ value of 5.0 was chosen for further experiments.

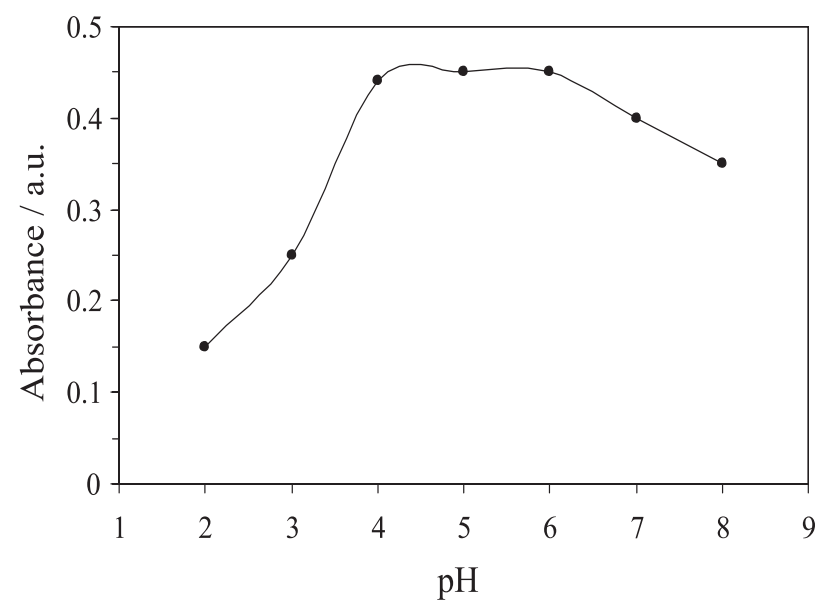

Figure 2. Effect of $\mathrm{pH}$ on the absorbance of the Zn-HENO complex. Conditions: zinc $10 \mu \mathrm{g} \mathrm{L}^{-1}$, HENO $2.0 \times 10^{-2} \mathrm{~mol} \mathrm{~L}^{-1}$, [Hmim] $\left[\mathrm{BF}_{4}\right] 30 \mathrm{mg}$, $\mathrm{NaPF}_{6} 100 \mathrm{mg}$ and diluting solvent $50 \mu \mathrm{L}$.

\section{Selection of the diluting solvent}

In order to decrease the viscosity of IL-phase, it must be diluted, thus different solvents were tested. The diluting solvent must completely dissolve IL and the complex. The solvents such as acetone (20-90\%), acetonitrile (20-70\%) and ethanol (40-90\%) were examined. As shown in Figure 3, in the presence of $80 \%$ ethanol, the solution was clear and the maximum absorbance was obtained. Therefore, ethanol $80 \%$ was chosen as the diluting solvent. In the presence of $30 \%$ acetone and acetonitrile, IL-phase could not be completely dissolved, and the solution was turbid. In order to enhance the sensitivity and the enrichment factor, the effect of the volume of the diluting solvent was investigated. The absorbance decreased by increasing the volume of the diluting solvent (Figure 4). Therefore, a volume of $50 \mu \mathrm{L}$ ethanol $80 \%$ was chosen to dilute the IL-phase. 


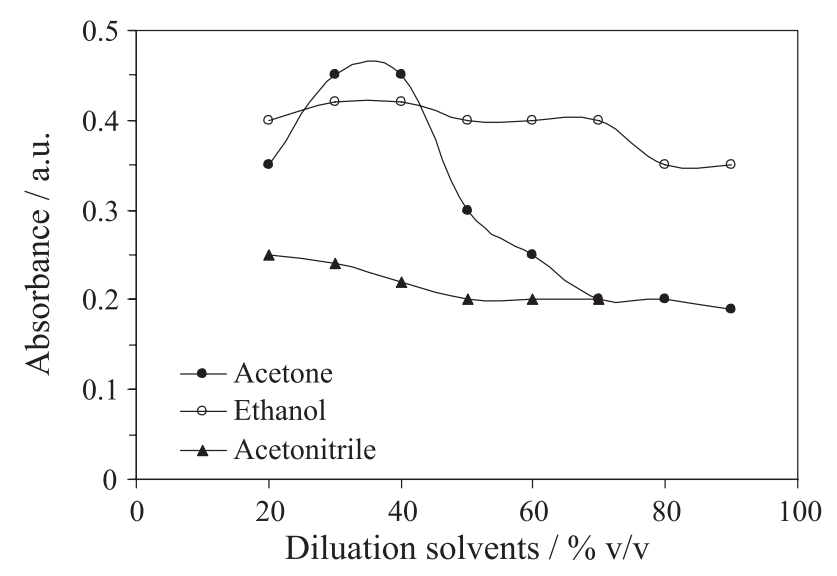

Figure 3. Effect of the type of the diluting solvent on the absorbance of $\mathrm{Zn}$-HENO complex. Conditions: zinc $10 \mu \mathrm{g} \mathrm{L}{ }^{-1}$, HENO $2.0 \times 10^{-2} \mathrm{~mol} \mathrm{~L}^{-1}$, $[\mathrm{Hmim}]\left[\mathrm{BF}_{4}\right] 30 \mathrm{mg}, \mathrm{NaPF}_{6} 100 \mathrm{mg}$ and diluting solvent $50 \mu \mathrm{L}$.

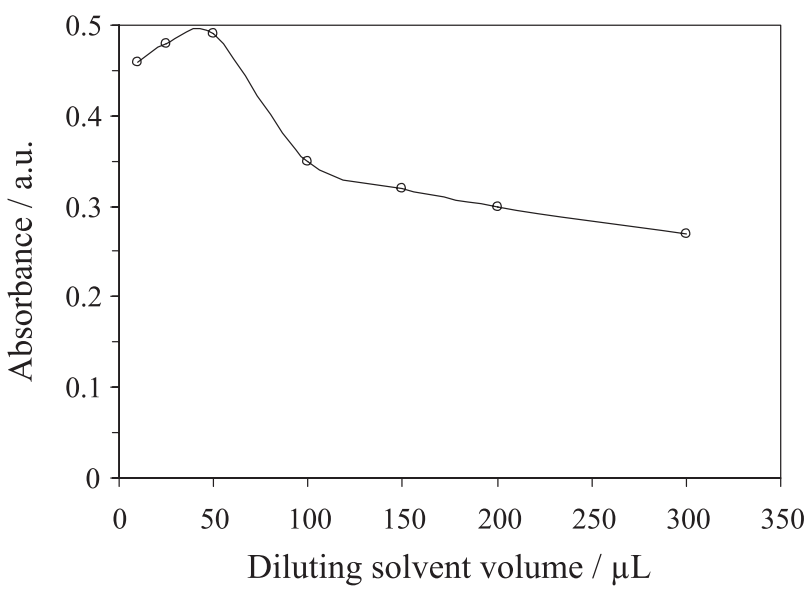

Figure 4. Effect of the volume of the diluting solvent (ethanol 80\%) on the absorbance of the Zn-HENO complex. Conditions: zinc $10 \mu \mathrm{g} \mathrm{L}^{-1}$, HENO $2.0 \times 10^{-2} \mathrm{~mol} \mathrm{~L}^{-1}$, $[\mathrm{Hmim}]\left[\mathrm{BF}_{4}\right] 30 \mathrm{mg}$ and $\mathrm{NaPF}_{6} 100 \mathrm{mg}$.

\section{Effect of the salt content}

In the presence of high content of salts, the solubility of ILs increases and the phase separation cannot occur. However, according to the common ion effect, the solubility decreases in the presence of common ion. $\mathrm{Na}_{2} \mathrm{SO}_{4}$ was chosen in order to study the salt effect. As shown in Figure 5, in excess of $\mathrm{NaPF}_{6}$, the phase separation successfully occurred up to $30 \% \mathrm{Na}_{2} \mathrm{SO}_{4}$. At higher salt content, the density of the solution became higher than that of IL so, the extract ant phase did not settle.

\section{Effect of $\mathrm{NaPF}_{6}$}

In order to decrease the solubility of IL-phase in brines, $\mathrm{NaPF}_{6}$ was added to the sample solutions as an ion-pairing agent. As a consequence of the reaction between the water-miscible IL and the ion-pairing agent, a water-immiscible IL with very low solubility must be

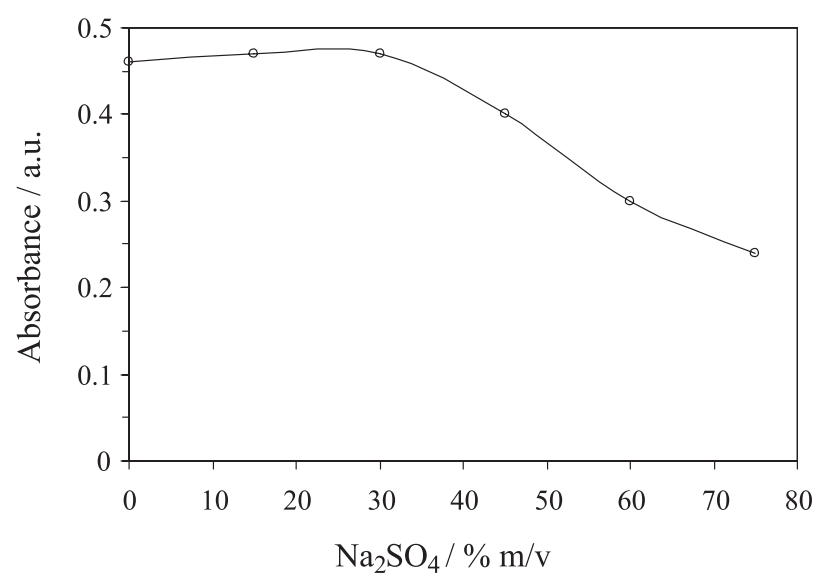

Figure 5. Effect of $\mathrm{Na}_{2} \mathrm{SO}_{4}$ on the absorbance of the $\mathrm{Zn}-\mathrm{HENO}$ complex. Conditions: Zinc $10 \mu \mathrm{g} \mathrm{L}^{-1}$, HENO $2.0 \times 10^{-2} \mathrm{~mol} \mathrm{~L}^{-1}$, [Hmim] $\left[\mathrm{BF}_{4}\right] 30 \mathrm{mg}$, $\mathrm{NaPF}_{6} 100 \mathrm{mg}$ and diluting solvent $50 \mu \mathrm{L}$.

formed. Ion-pairing agent must have no interference in the extraction system. The solubility of IL decreases according to the common ion effect so, the phase separation can successfully occur. The effect of $\mathrm{NaPF}_{6}$ was investigated in the range of 25-200 $\mathrm{mg}$ in the presence of $30 \mathrm{mg}$ [Hmim] $\left[\mathrm{BF}_{4}\right]$ and the results are shown in Figure 6. By adding $\mathrm{NaPF}_{6}$, $[\mathrm{Hmim}]\left[\mathrm{PF}_{6}\right]$ was formed and according to the common ion effect by increasing the amount of $\mathrm{NaPF}_{6}$, the solubility of $[\mathrm{Hmim}]\left[\mathrm{PF}_{6}\right]$ decreased and the absorbance subsequently increased. Thus, the amount of $100 \mathrm{mg} \mathrm{NaPF}_{6}$ was chosen for the subsequent experiments.

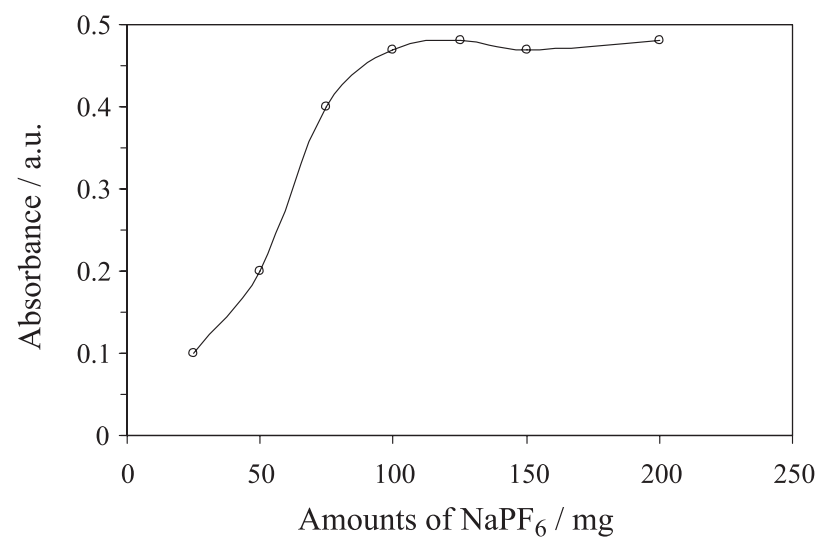

Figure 6. Effect of the amount of $\mathrm{NaPF}_{6}$ on the absorbance of the Zn-HENO complex. Conditions: zinc $10 \mu \mathrm{g} \mathrm{L}{ }^{-1}$, HENO $2.0 \times 10^{-2} \mathrm{~mol} \mathrm{~L}^{-1}$, $[\mathrm{Hmim}]\left[\mathrm{BF}_{4}\right] 30 \mathrm{mg}$ and diluting solvent $50 \mu \mathrm{L}$.

\section{Effect of the ionic liquid amount}

The amount of $[\mathrm{Hmim}]\left[\mathrm{BF}_{4}\right]$ that is used in this preconcentration procedure is a critical factor to obtain high recovery. Therefore, the extraction system was carefully studied in order to define the lowest IL-phase volume that is necessary for achieving the highest recovery. The effect of $[\mathrm{Hmim}][\mathrm{BF} 4]$ was studied in the range of $5-60 \mathrm{mg}$ in 
the presence of $100 \mathrm{mg} \mathrm{NaPF}$. As can be seen in Figure 7, the absorbance increased by increasing the amount of $[\mathrm{Hmim}]\left[\mathrm{BF}_{4}\right]$, and then, gradually decreased due to the increase in the volume of the settled phase. Thus, the amount of $30 \mathrm{mg}[\mathrm{Hmim}]\left[\mathrm{BF}_{4}\right]$ was chosen for the subsequent experiments.

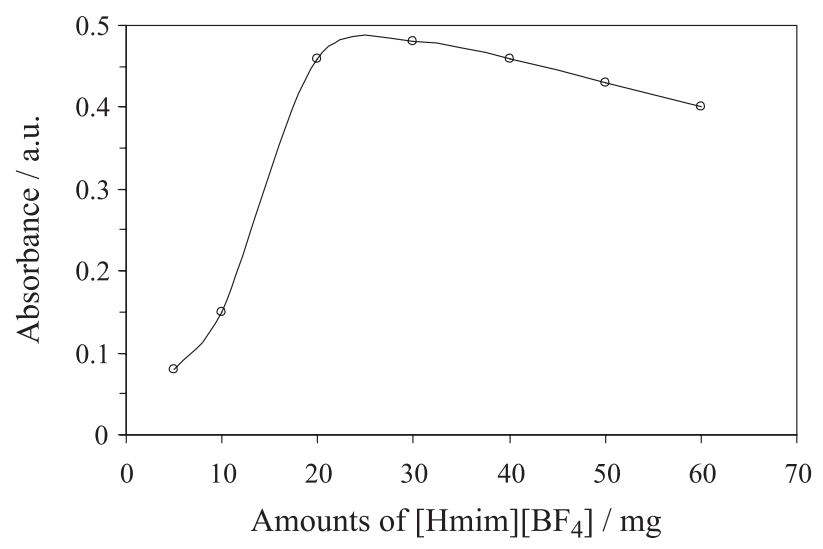

Figure 7. Effect of $[\mathrm{Hmim}]\left[\mathrm{BF}_{4}\right]$ on the absorbance of the $\mathrm{Zn}-\mathrm{HENO}$ complex. Conditions: zinc $10 \mu \mathrm{g} \mathrm{L}{ }^{-1}$, HENO $2.0 \times 10^{-2} \mathrm{~mol} \mathrm{~L}^{-1}, \mathrm{NaPF}_{6}$ $100 \mathrm{mg}$ and diluting solvent $50 \mu \mathrm{L}$.

\section{Effect of the HENO concentration}

The effect of HENO on the absorbance of the complex was studied in the range of $5.0 \times 10^{-4}-5.0 \times 10^{-2} \mathrm{~mol} \mathrm{~L}^{-1}$. The absorbance increased by increasing of the HENO concentration up to $2.0 \times 10^{-2} \mathrm{~mol} \mathrm{~L}^{-1}$ and then, remained constant (Figure 8). Therefore, a concentration of $2.0 \times 10^{-2} \mathrm{~mol} \mathrm{~L}^{-1}$ was chosen as the optimum concentration.

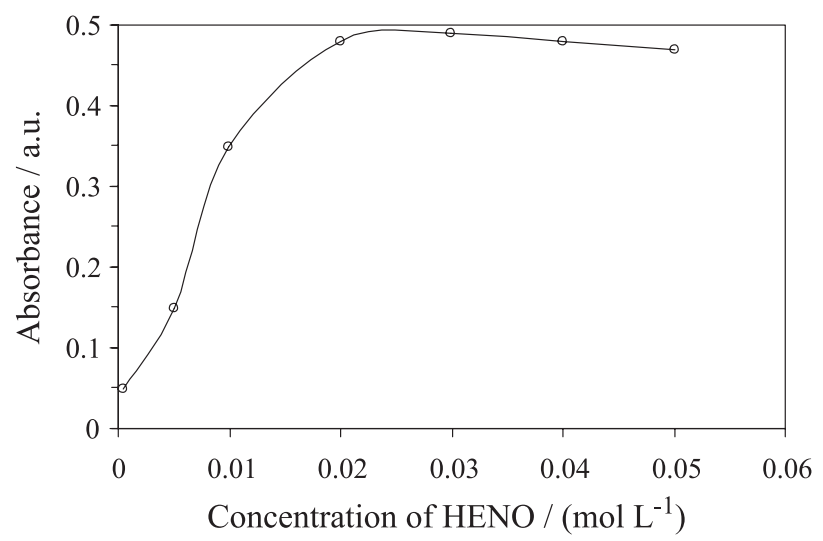

Figure 8. Effect of the HENO concentration on the absorbance of the Zn-HENO complex. Conditions: zinc $10 \mu \mathrm{g} \mathrm{L} \mathrm{L}^{-1},[\mathrm{Hmim}]\left[\mathrm{BF}_{4}\right] 30 \mathrm{mg}$, $\mathrm{NaPF}_{6} 100 \mathrm{mg}$ and diluting solvent $50 \mu \mathrm{L}$.

\section{Effect of the centrifuge rate}

The effect of the centrifugation rate on the absorbance was studied in the range of 500-5000 rpm. It was found that over $3500 \mathrm{rpm}$, IL-phase completely settled, hence
$4000 \mathrm{rpm}$ was selected as the optimum point. At the optimum rate, absorbance was investigated as a function of centrifugation time. The absorbance was constant beyond $5 \mathrm{~min}$, indicating the complete transfer of IL-phase to the bottom of centrifuge tube. So, the optimum centrifugation time of 6 min was chosen.

\section{Effect of foreign ions}

To assess the possible applications of the present procedure, the effect of foreign ions which may interfere with the determination of zinc or/and often coexisting in various real samples was examined. The interferences were studied by analyzing $10 \mathrm{~mL}$ of a solution containing $20 \mu \mathrm{g} \mathrm{L}^{-1} \mathrm{Zn}(\mathrm{II})$ and other ions at different concentrations, according to the recommended extraction procedure. Table 1 shows the tolerance limits of the interfering ions. An ion was considered to interfere when its presence produced a variation of more than $\pm 5 \%$ in the absorbance of the analyte. Commonly encountered ions such as alkali and some alkaline earth elements do not form stable complexes with HENO. However, $\mathrm{Cu}^{2+}$ interfered with the determination of $\mathrm{Zn}^{2+}$ in a maximum ratio of 20 . This interference was eliminated using an excess of HENO reagent in sample solutions or by masking it with a suitable reagent, such as thiourea.

Table 1. Tolerance limits of interfering in the determination of $20 \mu \mathrm{g} \mathrm{L}^{-1} \mathrm{Zn}^{2+}$

\begin{tabular}{lcc}
\hline Ions & $\begin{array}{c}\text { Tolerance limits } \\
\text { (mol ratio) }\end{array}$ & Recovery / \% \\
\hline $\mathrm{Na}^{+}, \mathrm{K}^{+}, \mathrm{Ca}^{2+}, \mathrm{Mg}^{2+}, \mathrm{Ba}^{2+}$ & $>100000$ & 99.8 \\
$\mathrm{Fe}^{2+}$ & 200 & 98.5 \\
$\mathrm{Fe}^{3+}$ & 1000 & 100.1 \\
$\mathrm{Mn}^{2+}$ & 250 & 98.5 \\
$\mathrm{Cd}^{2+}, \mathrm{Pb}^{2+}$ & 500 & 98.4 \\
$\mathrm{Ni}^{2+}$ & 50 & 99.3 \\
$\mathrm{Co}^{2+}$ & 50 & 99.2 \\
$\mathrm{NO}_{3}^{-}, \mathrm{Cl}^{-}, \mathrm{SO}_{4}^{2-}$ & 500 & 98.2 \\
$\mathrm{Br}^{-}$ & 1000 & 99.6 \\
$\mathrm{Cu}^{2+}$ & 20 & 99.1 \\
\hline
\end{tabular}

Figures of merit

The sensitivity of the developed method is reflected by the limit of detection (LOD) studies, being defined as the lowest concentration of metal ions below which the quantitative sorption of the metal ion by basic alumina is not perceptibly seen. Table 2 summarizes the analytical characteristics of the optimized method, including limit of detection, reproducibility and enhancement factor. The limit of detection $\left(\mathrm{LOD}=0.05 \mu \mathrm{g} \mathrm{L}^{-1}\right.$ ) was calculated as $3 \mathrm{~S}_{\mathrm{b}} / \mathrm{m}$ 
$\left(\mathrm{S}_{\mathrm{b}}\right.$ is the standard deviation of the blank signals and $\mathrm{m}$ is the slope of calibration curve after preconcentration). The precision of the method for the determination of $10 \mu \mathrm{g} \mathrm{L}^{-1}$ zinc was investigated for 8 replicate measurements and, a relative standard deviation of $0.8 \%$ was obtained. The calibration curve was investigated between 5.0-500.0 $\mu \mathrm{g} \mathrm{L}-1$ which was linear. Enhancement factor $(\mathrm{EF}=81)$ was obtained from the slope ratio of the calibration curve after and before preconcentration.

Table 2. Analytical figures of merit of the method

\begin{tabular}{lc}
\hline Parameter & Optimized value \\
\hline linear range / $\left(\mu \mathrm{g} \mathrm{L}^{-1}\right)$ & $5.0-500.0$ \\
limit of detection $(\mathrm{LOD}) /\left(\mu \mathrm{g} \mathrm{L}^{-1}\right)^{\mathrm{a}}$ & 0.05 \\
R.S.D. / \% $(\mathrm{n}=6)^{\mathrm{b}}$ & 0.8 \\
enhancement factor $^{\mathrm{c}}$ & 81 \\
\hline
\end{tabular}

aDetermined as $3 \mathrm{~S}_{\mathrm{b}} / \mathrm{m}$ (where $\mathrm{S}_{\mathrm{b}}$ and $\mathrm{m}$ are the standard deviation of the blank signal and the slope of the calibration graph, respectively); ${ }^{\text {bvalues }}$ in parentheses are the $\mathrm{Zn}$ concentration $\left(\mu \mathrm{g} \mathrm{L} \mathrm{L}^{-1}\right)$ for which the R.S.D. was obtained; ccalculated as the slope ratio of the calibration graph obtained with and without preconcentration.

\section{Analysis of real and reference samples}

The feasibility of the methodology for the determination of zinc in water samples (Zanjan City, Iran) was explored by the standard addition method. The results for this study are presented in Table 3 for water samples. The recovery of spiked samples is reasonably satisfactory and was confirmed using the standard addition method which indicates the capability of the system in determining $\mathrm{Zn}$. A good agreement was obtained between the added and measured analyte amounts. The recovery values that were calculated for the added standards were always higher than $96 \%$, thus confirming the accuracy of the procedure and its independence from the matrix effects. In order to establish the validity of the proposed procedure, the method was applied to the determination of the content of the studied analyte $\mathrm{Zn}(\mathrm{II})$ in a standard reference material. Portions $(0.5 \mathrm{~g})$ of GBW07602 bush twigs and leaves (reference) were transferred into beakers, $10 \mathrm{~mL}$ of concentrated $\mathrm{HNO}_{3}$ and $3 \mathrm{~mL}$ of $\mathrm{H}_{2} \mathrm{O}_{2}(30 \%)$ were added. It was heated until the solution became transparent, continuously heated to near dryness and the residue was dissolved in $0.1 \mathrm{~mol} \mathrm{~L}^{-1} \mathrm{HCl}$. After adjustment of the $\mathrm{pH}$ to 8.0, the solution was made up to $50 \mathrm{~mL}$ with distilled water. The content of the studied elements was determined according to the recommend procedure. The results are presented in Table 3. As can be seen, the results are in agreement with reference values.

\section{Conclusions}

$[\mathrm{Hmim}]\left[\mathrm{BF}_{4}\right]$ was chosen as a green medium and an alternative to the traditional volatile organic solvents for this extraction system. The determination was carried out by flame atomic absorption spectrometry (FAAS). The in situ solvent formation microextraction (ISFME) technique was successfully used for the preconcentration of trace amount of zinc in saline samples. The relative standard deviation, the limit of detection and the linear range of this procedure are also satisfactory. This method is fast, simple, safe and robust against very high content of salt (up to 30\%). Therefore, ISFME is a powerful sample preparation technique for saline solutions and salt products that are used in food and pharmaceutical industries. The preconcentration method was successfully applied to the zinc determination in water samples and reference material, with good accuracy and reproducibility.

\section{Acknowledgement}

The authors express their appreciation to the Graduate School and Research Council of Zanjan University (Iran) for financial support of this work.

Table 3. Determination of $\mathrm{Zn}^{+2}$ in reference material, mineral, rain and tap water samples and the relative recoveries of spiked samples $(\mathrm{n}=3$ )

\begin{tabular}{|c|c|c|c|c|c|}
\hline Samples & Certified value / $\left(\mu \mathrm{g} \mathrm{L}^{-1}\right)$ & Added $\left.\mathrm{Zn}^{+2} /(\mu \mathrm{g} \mathrm{L})^{-1}\right)$ & Found / $\left(\mu \mathrm{g} \mathrm{L}^{-1}\right)$ & R.S.D. $/ \%$ & Recovery $/ \%$ \\
\hline Tap water & & $\begin{array}{c}0 \\
10 \\
50\end{array}$ & $\begin{array}{c}8.5 \pm 0.2 \\
18.7 \pm 0.6 \\
57.4 \pm 0.5\end{array}$ & $\begin{array}{l}0.8 \\
1.0 \\
0.6\end{array}$ & $\begin{array}{l}101.0 \\
96.10\end{array}$ \\
\hline Mineral water & & $\begin{array}{c}0 \\
10 \\
50\end{array}$ & $\begin{array}{c}\text { n.d. } \\
11.5 \pm 0.9 \\
51.1 \pm 1.5\end{array}$ & $\begin{array}{l}0.9 \\
0.4 \\
0.6\end{array}$ & $\begin{array}{l}115.0 \\
105.5\end{array}$ \\
\hline Rain water & & $\begin{array}{c}0 \\
10 \\
50\end{array}$ & $\begin{array}{c}8.0 \pm 0.3 \\
19.2 \pm 0.9 \\
58.5 \pm 1.2\end{array}$ & $\begin{array}{l}0.5 \\
1.0 \\
0.9\end{array}$ & $\begin{array}{l}106.6 \\
101.7\end{array}$ \\
\hline GBW07602 & $40.0 \pm 3.0$ & & $38.0 \pm 2.0$ & 0.4 & 97.0 \\
\hline
\end{tabular}

All values are in $\mu \mathrm{g} \mathrm{L}^{-1}$; n.d.: not detected. 


\section{References}

1. Sattar, A.; Ahmad, B.; Jamshaid, M.; Pak. J. Agric. Sci. 1990, 27, 156.

2. Fosmire, G. J.; Am. J. Clin. Nutr. 1990, 51, 225.

3. Brita, T. A. M.; Karel, A. C. S.; Colin, R. J.; Aquat. Toxicol. 2006, 77, 393

4. Ferreira, S. L. C.; Andrade, J. B.; Korn, M. G. A.; Pereira, M. G.; Lemos, V. A.; Santos, W. N. L.; Rodrigues, F. M.; Souza, A. S.; Ferreira, H. S.; Silva, E. G. P.; J. Hazard. Mater. 2007, 145, 358.

5. Anthemidis, A. N.; Zachariadis, G. A.; Stratis, J.A.; Talanta 2001, 54, 935

6. Hosseini, M.; Dalali, N.; Karimi, A.; Dastanra, K.; Turk. J. Chem. 2010, 38, 805.

7. Divrikli, U.; Akdogan, A.; Soylak, M.; Elci, L.; J. Hazard. Mater. 2007, 149, 331.

8. Ghaedi, M.; Niknam, K.; Taheri, K.; Hossainian, H.; Soylak, M.; Food Chem. Toxicol. 2010, 48, 891.

9. Tuzen, M.; Soylak, M.; Elci, L.; Dogan, M.; Anal. Lett. 2004, $37,1185$.

10. Guidotti, M.; J. AOAC Int. 2000, 83, 1082.

11. Kole, P. L.; Millership, J.; McElnay, J. C.; J. Pharm. Biom. Anal. 2011, 54, 701.

12. Gil, S.; Loos-Vollebregt, M. T. C.; Bendicho, C.; Spectrochim. Acta, Part B 2009, 64, 208.
13. Jiang, H.; Hu, B.; Chen, B.; Zu, W.; Spectrochim. Acta, Part B 2008, 63, 770 .

14. Kulichenko, S. A.; Doroschuk, V. O.; Lelyushok, S. O.; Talanta 2003, 59, 767.

15. Tuzen, M.; Melek, E.; Soylak, M.; J. Hazard. Mater. 2008, 159, 335.

16. Liang, P.; Sang, H.; Anal. Biochem. 2008, 380, 21.

17. Gharehbaghi, M.; Shemirani, F.; Davudabadi Farahani, M.; J. Hazard. Mater. 2009, 165, 1049.

18. Mahpishanian, S.; Shemirani, F.; Talanta 2010, 82, 471.

19. Abdolmohammad-Zadeh, H.; Sadeghi, G. H.; Anal. Chim. Acta 2009, 649, 211.

20. Rogers, R. D.; Seddon, K. R.; Ionic Liquids as Green Solvents: Progress and Prospects, ACS Symposium Series 856; American Chemical Society: Washington, DC, 2003.

21. Welton, T; Chem. Rev. 1999, 99, 2071.

22. Visser, A. E.; Swatloski, R. P.; Reichert, W. M.; Griffin, S. T.; Rogers, R. D.; Ind. Eng. Chem. Res. 2000, 39, 3596.

23. Fischer, H.; Org. Synth. Coll. 1955, 3, 513.

24. Semon, W. L.; Damerell, V. R.; Org. Synth., Coll. 1943, $2,204$.

25. Hartung, W. H., Crossley, F.; Org. Synth., Coll. 1943, 2, 363.

Submitted: July 8, 2011

Published online: October 18, 2011 